\title{
Red Blood Cell Transfusion in the Neurological ICU
}

\author{
Monisha A. Kumar
}

Published online: 28 December 2011

(C) The American Society for Experimental NeuroTherapeutics, Inc. 2011

\begin{abstract}
Red blood cell transfusion (RBCT) is a common therapy used in the intensive care unit to treat anemia. However, due to deleterious side effects and questionable efficacy, the clinical benefit of RBCT in patients who are not actively bleeding is unclear. The results of randomized controlled trials suggest there is no benefit to a liberal transfusion practice in general critical care populations. Whether the results of these trials are applicable to brain injured patients is unknown, as patients with primary neurological injury were excluded. This article reviews the efficacy and complications of RBCT, as well as the relationship between RBCT and its outcome in both the general intensive care unit and neurologically critically ill populations.
\end{abstract}

Keywords Anemia, Transfusion, ICU, Erythrocytes, Hemoglobin, Neurocritical care

\section{Efficacy of Red Blood Cell Transfusions}

Red blood cell transfusions (RBCTs) are intended to improve tissue oxygenation; however, whether they do so remains unclear. The notion that RBCT augments tissue perfusion presumes that transfused blood efficiently stores and offloads oxygen, and that compromised tissues utilize

M. A. Kumar $(\bowtie)$

Departments of Neurology, Neurosurgery,

Anesthesiology \& Critical Care, University of Pennsylvania,

Perelman School of Medicine,

3400 Spruce Street 3 West Gates,

Philadelphia, PA 19104, USA

e-mail: Monisha.Kumar@uphs.upenn.edu the additional oxygen. However, studies have shown that although transfusion increases oxygen carrying capacity by augmenting hemoglobin concentration, it often fails to increase oxygen utilization [1-5]. The inability of transfused blood to increase tissue perfusion has been attributed to a series of biochemical and biomechanical changes that occur during red blood cell (RBC) storage collectively termed the "storage lesion."

The storage lesion results in decreased oxygen delivery to tissues. After 7 days, stored blood is depleted of 2,3-diphosphoglycerate, a compound that is responsible for enhancing oxygen release from hemoglobin to tissues [6,7]. A loss of 2,3-diphosphoglycerate in stored blood shifts the oxygen dissociation curve to the left and reduces the amount of oxygen available for tissue consumption. Furthermore, time-dependent changes in stored blood lead to acidemia and hyperkalemia, which result in RBC lysis and release of free hemoglobin [8]. Free hemoglobin is a nitric oxide scavenger and therefore may result in vasoconstriction and exacerbation of organ dysfunction [9].

Structural changes, induced by RBC storage, have been shown to compromise microvascular circulation [10]. RBCs undergo a predictable change from biconcave disks to sphero-echinocytes, resulting in loss of deformability. The loss of the biconcave structure of the $8-\mu \mathrm{m}$ erythrocyte impairs its ability to navigate capillaries with smaller diameters (e.g., 3-8 $\mu \mathrm{m}$ ) and may result in vessel occlusion. Sphero-echinocytes result from microvesiculation and loss of surface-to-volume ratio. The formation of microvesicles is associated with increased osmotic fragility and decreased RBC survival [11, 12]. Depletion of adenosine tri-phosphate may also contribute to corpuscular changes [13]. Storage duration of greater than 42 days may cause vasoconstriction due to lysophosphatidyl choline species released from the 
cellular membrane of senescent RBCs [14]. The storage lesion also promotes increased $\mathrm{RBC}$ aggregability and $\mathrm{RBC}$ endothelial cell adhesion, which may compromise or obstruct microvascular circulation $[15,16]$. Part of this effect may be mediated by microparticles, anucleoid membrane vesicles, which increase in concentration with storage duration $[17,18]$. Microparticles have been implicated in posttransfusion thrombosis likely due to the expression of phosphatidyl serine, which promotes plasma-mediated thrombin generation [17-19].

In summary, RBCT may not accomplish the intended effect of improved tissue oxygenation. The lack of efficacy is mediated in part by the storage lesion.

\section{Complications of Transfusions}

Blood transfusion therapy is associated with adverse side effects, including transmission of infections and immune activation or immunosuppression. Both viral illness and prion diseases may be transmitted by blood transfusion. Risks of transmission of human immunodeficiency virus, hepatitis $\mathrm{C}$ virus, and hepatitis B virus are 1 in 1,900,000; 1 in 600,000; and 1 in 220,000, respectively [20]. Cytomegalovirus is present in $4 \%$ of transfusions from healthy donors due to the reactivation of latent cytomegalovirus in leukocytes [21, 22].

Transfusion modulates the immune system in 2 opposite ways: 1) it may heighten the immune response ("alloimunization"), as in transfusion reactions, or it may quell the immune response ("tolerance induction"), which predisposes to nosocomial infections. Human leukocyte antigens (HLA), specifically HLA-DR antigens, on donor leukocytes partly determine which response ensues following RBCT; shared HLA-DR antigens between donor and recipient induce tolerance, whereas antigenic mismatch results in immunization [23].

Alloimmunization and consequent induction of HLA antibodies and T-cell activation results in a number of clinical syndromes, including transfusion reactions, transfusion associated graft-versus-host disease, transfusion-related acute lung injury, and potentially the development of various autoimmune diseases [23]. Transfusion-related acute lung injury is the number 1 cause of transfusion-related mortality $[24,25]$. Transfusion-related acute lung injury is defined as a new episode of respiratory distress, which is not explained by an alternate etiology that occurs during or within $6 \mathrm{~h}$ of a completed transfusion [26]. The most common clinical features include: bilateral pulmonary edema, hypoxemia, fever, dyspnea, and hypotension in the presence of normal cardiac function [27]. Plasma-rich blood components (fresh frozen plasma and platelets) and high-volume transfusion may predispose to transfusion-related acute lung injury, although it has been associated with all blood product components including intravenous immunoglobulin $\mathrm{G}$ and cryoprecipitate [28-30].

Tolerance induction after RBCT is associated with a decrease in natural killer cell function, defective antigen presentation, and a reduction in helper/suppressor $\mathrm{T}$ lymphocyte ratio, and has been linked to increased predisposition to nosocomial and postoperative infections and even to cancer recurrence [31-39]. Transfusion has been associated with increased risk of infection in cardiac surgery patients [40-42], trauma patients [32-35], and critically ill patients [43, 44]. Of 45 studies included in a meta-analysis of transfusion in the intensive care unit (ICU), 22 studies examined the effect of transfusion on infection and all demonstrated an independent association [45]. The pooled odds ratio for developing an infectious complication was 1.8 (95\% CI, 1.5-2.2). Transfusion was also associated with an increased risk of multi-organ dysfunction and acute respiratory distress syndrome.

Clinical side effects due to the storage lesion result not only from erythrocyte changes, but also from leukocyte changes. Transfusion-transmitted infections are thought to be due to contaminated leukocytes [46]. Donor leukocytes secrete cytokines, which have been associated with both febrile nonhemolytic transfusion reactions and hemolytic transfusion reactions, in a time-dependent manner after storage [47]. Accumulation of lipid mediators, capable of priming recipient neutrophils and exacerbating multi-organ dysfunction, may result from leukocyte activity on RBC membranes during storage $[48,49]$. Leukocyte degradation during storage results in release of oxygen free radicals and proteases, which may also incite inflammation in the transfusion recipient [50].

Leukoreduction of stored blood might mitigate the immunomodulatory effects of transfused RBCs, but its clinical impact and cost-effectiveness have not been fully studied. Although leukoreduction has been shown to reduce the rate of febrile nonhemolytic transfusion reactions [51], it has not consistently prevented such reactions [52]. A Canadian study, in which 7000 patients treated after institution of universal leukoreduction were compared to 7000 historical controls, suggested that universal leukoreduction was associated with lower mortality, but not a significant decrease in infection rate [53]. Smaller randomized controlled clinical trials of LR have failed to demonstrate any beneficial effect of leukoreduction on clinical outcome, including in-hospital mortality, ICU length of stay (LOS), and antibiotic usage [54-56]. Although the utility and cost-effectiveness of universal leukoreduction remains controversial, the majority of blood banking centers in the United States have followed the lead of Canada by adopting this practice, given the putative benefit and minimal risk. 


\section{Transfusion Practice in General ICUs}

Transfusion is commonly used to improve cellular oxygen metabolism in sepsis and other shock states; however, physiological studies of its effects on tissue perfusion have not consistently demonstrated benefit [57-59]. Although RBCT, as part of a bundled approach to early sepsis management, did confer a survival advantage in a landmark study of patients with septic shock [60], subsequent studies have not confirmed this finding [61]. It should be noted that RBCT remains a recommendation of the 2008 Surviving Sepsis Campaign guideline as part of an algorithm for the treatment of sepsis.

Transfusion administration has been shown to exacerbate sepsis-related microcirculatory dysfunction and impair tissue perfusion. In a study of patients with sepsis, splanchnic perfusion, as measured by gastric tonometry, did not improve after transfusion [62]. In another study, transfusion of 3 units of RBCs did not measurably increase systemic oxygen uptake; however, it did result in splanchnic ischemia in those who had received blood stored for $>15$ days [63].

Prospective, multicenter observational studies suggest an association between RBCT and increased mortality and morbidity in general ICUs [64, 65]. The Anemia, Blood Transfusion in Critically Ill Patients (ABC) trial demonstrated that transfused patients had more severe organ failure, increased LOS, and higher mortality rates than nontransfused patients [64]. Higher mortality rates were observed regardless of admission hemoglobin level, thereby accounting for any effect of pre-morbid anemia. A dose-response relationship was identified between number of units transfused and mortality; the mortality rate for patients receiving 1 unit of RBCs was $15.9 \%$, whereas those receiving $>4$ units it was $44.8 \%$. Overall, RBCT increased the odds of death by a factor of 1.4. Propensity score analysis, performed on a subset of patients, demonstrated a higher mortality rate for those transfused, and this coupled with the fact that mortality rates were higher for transfused patients at nearly all levels of organ dysfunction, suggested that transfusionrelated mortality was not simply a surrogate for increased severity of illness. A meta-analysis of transfusion therapy in the ICU concluded that transfusion was an independent predictor of mortality in critically-ill adult, trauma and surgical patients [45].

Concern about the safety and efficacy of red blood cell transfusion, including immunosuppressive and microcirculatory complications, has led to a reappraisal of transfusion practices. The Transfusion Requirements in Critical Care (TRICC) trial was designed to determine whether restrictive and liberal transfusion strategies in the ICU produces equivalent all-cause mortality at 30 days and equivalent organ dysfunction [66]. In this randomized controlled study, a hemoglobin threshold of either $7 \mathrm{~g} / \mathrm{dL}$ or $10 \mathrm{~g} / \mathrm{dL}$ was targeted as a trigger for transfusion to maintain hemoglobin concentrations in the goal ranges of 7 to $9 \mathrm{~g} / \mathrm{dL}$ and 10 to $12 \mathrm{~g} / \mathrm{dL}$, respectively. The primary endpoint of the 30-day mortality was not significantly different between the 2 groups; however, in patients with an Acute Physiology and Chronic Health Evaluation II (APACHE II) score of $<20$, or 55 years of age, a restrictive approach was favorable ( $p=$ 0.03 and $p=0.02$, respectively). Thirty-day mortality rates between treatment groups were not significantly different in the subgroups of patients with cardiac disease, severe infections or septic shock, or trauma. Although no significant difference in mortality rates was observed for the subset of patients with cardiovascular disease, there were significantly more cardiac complications in the liberal transfusion arm than in the restrictive arm $(21.0 \%$ vs $13.2 \% ; p<0.01)$. The authors recommended that critically ill patients receive RBCT when the hemoglobin concentration falls below $7.0 \mathrm{~g} / \mathrm{dl}$, and it is also recommend that hemoglobin levels be maintained between 7.0 and $9.0 \mathrm{~g} / \mathrm{dl}$.

A similar study was performed in a larger cohort of patients admitted for hip surgery with a history of risk factors for cardiovascular disease [67]. Approximately 2000 patients were randomized to transfusion, either when clinically symptomatic or at an arbitrary threshold of $10 \mathrm{~g} /$ $\mathrm{dL}$. The primary outcome was death or inability to walk unassisted for a pre-specified distance at 60 days. There was no significant difference in outcome between the high threshold and symptomatic groups. The authors concluded that a symptomatic transfusion practice conserved blood and did not negatively impact outcomes in elderly patients with underlying cardiovascular disease or cardiovascular risk factors.

In the general critical care population, RBCT has been associated with increased mortality and morbidity. Although the TRICC trial provides the best evidence for transfusion practice in the management of the critically ill, it should be recognized that patients with primary neurological injury were excluded.

\section{Impact of Transfusion in the Neuro-ICU}

\section{Ischemic Stroke}

Although trials studying RBCT in ischemic stroke are lacking, many trials exist studying the relationship between hematocrit and ischemic stroke. Although it seems intuitive that augmentation of oxygen carrying capacity $\left(\mathrm{CaO}_{2}\right)$ and oxygen delivery $\left(\mathrm{DO}_{2}\right)$ might ameliorate symptoms of an ischemic disease, concerns about viscosity-related reductions in cerebral blood flow (CBF) have limited consideration of 
RBCT in stroke. Conversely, hemodilution has been studied extensively as a putative treatment option for ischemic stroke because of the inverse relationship between hematocrit, the main determinant of viscosity, and CBF, although it has not been shown to improve outcome [68].

It has been postulated that increased viscosity exacerbates stasis, compromising microcirculatory blood flow to the ischemic penumbra [69]. In support of this theory, Allport et al. [70] demonstrated that higher baseline hematocrit $(>50 \%)$ was associated with expansion of infarction and less reperfusion [70]. This effect may be more pronounced in women with hematocrit $>50 \%$ [71]. Moreover, elevated hematocrit levels have been associated with carotid atherosclerosis [72, 73], atrial fibrillation [74], unilateral cerebral infarction [75], greater infarct size [75], early mortality [71, 74], and major disability after stroke [76].

Other studies have noted a "U-" or "reverse J"-shaped relationship between hematocrit and increased risk of stroke $[74,77,78]$, suggesting that not only high hematocrit concentrations $(>50 \%)$, but also low hematocrit concentrations $(<30 \%)$ are also associated with an increased risk of ischemic stroke [79]. Reduced admission hemoglobin concentrations have been associated with larger infarct volume and infarct expansion on magnetic resonance imaging, and hemoglobin and hematocrit nadir have been associated with poor outcome [80]. Failure of compensatory autoregulation and oxygen extraction due to active ischemia was proposed as the mechanism of reduced oxygen use and infarction. Low baseline and intraoperative hemoglobin and hematocrit have also been associated with postoperative strokes in cardiac surgery patients $[81,82]$, although this finding has been inconsistent [83, 84]. A study of more than 10,000 cardiac surgery patients found that each percent decrease in hematocrit from baseline resulted in a $10 \%$ increase in stroke risk [81]. Independent of hemoglobin concentration, intraoperative transfusion has been associated with increased postoperative stroke in patients undergoing cardiopulmonary bypass [82]. Further studies are needed to determine whether RBCT or other interventions to augment oxygen delivery might reduce cerebral ischemia in both acute ischemic stroke and cardiac surgery patients.

\section{Intracerebral Hemorrhage}

A dose-dependent relationship between anemia and intracerebral hemorrhage ( $\mathrm{ICH})$ volume has been demonstrated in the literature [85], and a single study exists regarding the effect of RBCT on outcome after ICH [86]. Sheth et al. [86] found that RBC transfusion was associated with improved survival at 30 days (odds ratio, 2.76; 95\% CI 1.45-5.26; $p=$ 0.002 ) and decreased mortality at 30 days (odds ratio, 0.40 ; 95\% CI 0.19-0.69; $p=0.02$ ). However, despite transfusion, there was no significant increase in hemoglobin concentration among patients who were transfused; therefore, the mechanism by which transfusion appeared to be protective remained elusive. The authors tried to reconcile their findings with the fact that restrictive strategies appear to be beneficial in general ICU patients. They postulated that predictors of mortality in general ICU populations may not be analogous to those in patients with $\mathrm{ICH}$, and thus the results may lead to different conclusions. They surmised that the benefit of transfusion might have been derived from augmented intravascular and/or cerebral blood volume given the fact that hemoglobin did not increase with time. Whether increased oxygen carrying capacity is required in the post-ICH period during times of cerebral edema, hydrocephalus, intracranial hypertension, or seizures remains unknown. Secondary injury after ICH, characterized by ironmediated neurotoxicity, macrophage activation, and matrix metalloproteinase upregulation, may further increase the demand for oxygen.

Anemia may be associated with increased hematoma volume, the primary predictor of mortality in patients with ICH. Whether transfusion can limit hematoma volume and improve outcome remains to be determined.

\section{Subarachnoid Hemorrhage}

The impact of transfusion on subarachnoid hemorrhage (SAH) outcome is largely unknown, and the relevant data are mainly derived from retrospective clinical studies and from physiologic studies. There exists relatively more data on the relationship between anemia and outcome in patients with SAH. Anemia consistently predicts, in a dosedependent fashion, infarction, death, and dependency [87, 88], and may also predict cognitive impairment [89]. Whether transfusion mitigates these risks is unknown.

Transfusion in patients after SAH is associated with poor outcome in some studies. A small prospective study of fluid therapy in $\mathrm{SAH}$ management found that RBCT was associated with poor outcome at discharge, but not at 6 months [90]. A single center, retrospective study found that discharge outcome in transfused patients was worse only in patients with arterial vasospasm [91]. Intraoperative transfusion also may be associated with poor 6-month outcome [92].

Red blood cell transfusion may be associated with increased risk of cerebral vasospasm [90]. In a retrospective study of 441 SAH patients, postoperative RBCT was associated with an increased risk of both angiographic and symptomatic vasospasm, independent of smoking, HuntHess grade, Fisher group, and intraoperative rupture [92]. It was postulated that transfused blood, depleted of nitric oxide, might result in a blunted vasodilatory response to vasospasm. 
Other retrospective studies have demonstrated an association between transfusion and increased frequency of cerebral and extra-cerebral complications in patients with SAH [93, 94]. Transfusion significantly increases the risk of major (cardiac, pulmonary, renal, or hepatic) and minor (rash, deep vein thrombosis) medical complications [93]. In a study of $620 \mathrm{SAH}$ patients, RBCT was identified as a risk factor associated with the development of acute lung injury, independent of severity of illness, clinical grade, and severe sepsis [95]. RBCT may be associated with an increased risk of infection and inflammation; this could prove particularly deleterious to the patient with $\mathrm{SAH}$, as infection has been shown to exacerbate delayed cerebral ischemia (DCI) and potentially worsen outcome in SAH $[45,96]$. Erythrocyte transfusion may also be associated with an increased risk of thrombotic events in SAH patients, independent of injury severity, baseline demographics, comorbid conditions, other blood component transfusion, and Transcranial Doppler U1trasound (TCD) vasospasm [97]. This may be explained by rheological and storage-induced changes in RBC structure, coupled with alterations in coagulation and fibrinolysis in $\mathrm{SAH}$ patients that may result in an increased risk of thrombosis.

Studies using physiological endpoints, such as cellular metabolism and brain hypoxia, have examined the relationship between hemoglobin concentration and cerebral metabolic dysfunction. Studies that used brain tissue oxygen tension $\left(\mathrm{P}_{\mathrm{bt}} \mathrm{O}_{2}\right)$ monitoring and lactate-to-pyruvate (LPR) measurements via cerebral microdialysis demonstrated increased brain hypoxia and cell energy dysfunction when hemoglobin levels were less than $9 \mathrm{~g} / \mathrm{dl}$ [98]. This association was independent of other factors such as cerebral perfusion pressure and vasospasm. Other studies have shown that reduced hemoglobin concentration was associated with hypoxia, impaired autoregulation, and increased cellular injury [99, 100]. One mathematical model suggested that hemoglobin concentrations $<10 \mathrm{~g} / \mathrm{dL}$ were associated with increased brain damage in animals with focal ischemia [79].

Physiological studies have also been used to examine the relationship between RBCT and outcome. In 1 study ${ }^{15}$-Oxygen labeled positron emission tomography $\left({ }^{15} \mathrm{O}\right.$ PET) was performed in $8 \mathrm{SAH}$ patients before and after transfusion of 1 unit of RBCs [101]. Transfusion resulted in a $15 \%$ rise in both hemoglobin concentration and $\mathrm{CaO}_{2}$, but did not reduce global $\mathrm{CBF}$, demonstrating that $\mathrm{CBF}$ may not be negatively impacted by changes in viscosity induced by transfusion of 1 unit RBCs. Although oligemic regions demonstrated improved $\mathrm{DO}_{2}$ and $\mathrm{CBF}$ after transfusion, $\mathrm{CBF}$ fell in areas of vasospasm. It was suggested that transfusion might improve perfusion-related reductions in $\mathrm{DO}_{2}$ in areas with preserved autoregulation, but not in territories affected by vasospasm. The authors concluded that RBC transfusion could provide benefits similar to
CBF augmentation (with intravenous crystalloid infusions and vasopressors), the current mainstay of DCI prevention.

At present, a multidisciplinary consensus panel of the Neurocritical Care Society strongly recommends that patients should receive RBCT to maintain a hemoglobin concentration $>8$ to $10 \mathrm{~g} / \mathrm{dl}$, based on moderate quality data [102]. A pilot study has shown that it is feasible to target hemoglobin thresholds and to prospectively assess outcome after transfusion; a prospective, randomized controlled trial to definitively determine transfusion thresholds in $\mathrm{SAH}$ patients is required [103].

\section{Traumatic Brain Injury}

There are no prospective randomized studies of transfusion in patients with traumatic brain injury (TBI), and data are largely derived from subgroup analyses of prospective studies in other populations. Trials in general trauma patients suggest that transfusion may increase the risk of both infection and mortality. Dunne et al. [104] demonstrated that transfusion of more than 4 units of blood increases the risk of death by a factor of 3 and increases the risk of perioperative infection by a factor of 9 [104]. In another study, blood transfusion was found to be an independent predictor of mortality, systemic inflammatory response syndrome, ICU admission, and increased ICU length of stay [38]. Trauma patients who receive blood transfusions have a twofold to sixfold increase in systemic inflammatory response syndrome and a more than fourfold increase in ICU admissions [38]. However, some studies of general trauma patients have failed to demonstrate a relationship between RBCT and adverse outcome [105]. In a substudy of the TRICC trial, 203 trauma patients, $25 \%$ of whom were identified as having brain injury, were randomized to a liberal versus restrictive strategy transfusion [106]. No significant differences in mortality, multiorgan dysfunction, ICU, or hospital LOS were identified. In a separate analysis, study results confirmed that a liberal transfusion strategy demonstrated no mortality benefit in a smaller cohort of patients with moderate-severe TBI [106].

Transfusion has been shown to improve $\mathrm{P}_{\mathrm{bt}} \mathrm{O}_{2}$ in 4 studies of severe TBI [107-110]; however, the magnitude of augmentation was small, the significance was questionable, and the effect was inconsistent. Interestingly, in 1 of these studies, RBCT resulted in a statistically significant increase in brain oxygenation; however, 13 of 30 patients $(43 \%)$ experienced a decline in $\mathrm{P}_{\mathrm{bt}} \mathrm{O}_{2}$ after $\mathrm{RBCT}$ [107]. In a study of 49 TBI patients with 564 episodes of compromised $\mathrm{P}_{\mathrm{bt}} \mathrm{O}_{2}$, blood transfusion improved compromised $\mathrm{P}_{\mathrm{bt}} \mathrm{O}_{2}$ only $50 \%$ of the time [111]. In contrast, interventions, such as fraction of inspired oxygen $\left(\mathrm{FiO}_{2}\right)$ augmentation, vasospressor utilization, hyperosmolar therapy, and benzodiazepine administration resulted in a $>70 \%$ response rate. 
The variable response to RBCT observed in patients with TBI may be due to the fact that secondary ischemia is less common than previously thought. Physiologic studies suggest that what was thought to represent ischemia may actually signify mitochondrial failure [6]. Cerebral microdialysis has traditionally been used to identify regional ischemia by sampling the interstitium for metabolites, such as glucose, lactate, and pyruvate. The principal marker of cerebral ischemia is the LPR. An LPR $>40$ has been correlated with PET evidence of regional brain ischemia, particularly in patients with SAH [112-114]. However, an elevated LPR has also been identified in TBI without evidence of ischemia; PET data suggest that an elevated LPR corresponds to nonischemic reductions in cerebral metabolic rate for oxygen, a measure of mitochondrial function [114-116]. Therefore, RBCT intended to improve compromised blood flow may not be warranted.

Optimal use of transfusion in TBI remains unclear. Data from subgroup analysis of the TRICC suggests that there may be no benefit to transfusion in TBI. However, this analysis lacks the necessary power to make definitive conclusions. A survey of physicians at trauma centers in the United States found that transfusion practice in TBI widely varied, and many clinicians held the belief that a restrictive transfusion threshold may be inappropriate for patients with intracranial hypertension [117].

\section{Conclusions}

It remains unclear whether RBCT to correct anemia in brain injury patients who are not actively bleeding is warranted. Although RBCT may augment brain oxygenation in compromised tissue, it may also result in a paradoxical decrease in perfusion. This variable effect may be the result of prolonged blood storage. It is possible that patients with impaired baseline perfusion benefit from RBCT more than those without. Transfusion may be more effective in patients with SAH, given the associated risk of DCI, whereas the ischemia previously identified in TBI patients may more accurately represent mitochondrial dysfunction less responsive to transfusion. Individualized transfusion therapy may be preferable, with use of physiological endpoints instead of arbitrary hemoglobin levels. Large, prospective, randomized controlled trials are needed to better define the role of anemia, optimal hemoglobin threshold, and utility of RBCT and are of paramount importance to improve the management of patients in the neurological ICU.

Required Author Forms Disclosures forms provided by the authors are available with the online version of this article.

\section{References}

1. Gramm J, Smith S, Gamelli RL, Dries DJ. Effect of transfusion on oxygen transport in critically ill patients. Shock 1996;5:190 193.

2. Mink RB, Pollack MM. Effect of blood transfusion on oxygen consumption in pediatric septic shock. Crit Care Med 1990;18:1087-1091.

3. Shah DM, Gottlieb ME, Rahm RL, et al. Failure of red blood cell transfusion to increase oxygen transport or mixed venous $\mathrm{PO} 2$ in injured patients. J Trauma 1982;22:741-746.

4. Kahn RC, Zaroulis C, Goetz W, Howland WS. Hemodynamic oxygen transport and 2,3-diphosphoglycerate changes after transfusion of patients in acute respiratory failure. Intensive Care Med 1986;12:22-25.

5. Dietrich KA, Conrad SA, Hebert CA, Levy GL, Romero MD. Cardiovascular and metabolic response to red blood cell transfusion in critically ill volume-resuscitated nonsurgical patients. Crit Care Med 1990;18:940-944.

6. Kramer AH, Zygun DA. Anemia and red blood cell transfusion in neurocritical care. Crit Care 2009;13:R89.

7. Apstein CS, Dennis RC, Briggs L, Vogel WM, Frazer J, Valeri CR. Effect of erythrocyte storage and oxyhemoglobin affinity changes on cardiac function. Am J Physiol 1985;248(4 part 2):H508-15.

8. Nishiyama T, Hanaoka K. Hemolysis in stored red blood cell concentrates: modulation by haptoglobin or ulinastatin, a protease inhibitor. Crit Care Med 2001;29:1979-1982.

9. Zallen G, Moore EE, Ciesla DJ, Brown M, Biffl WL, Silliman CC. Stored red blood cells selectively activate human neutrophils to release IL-8 and secretory PLA2. Shock 2000;13:29-33.

10. Card RT, Mohandas N, Perkins HA, Shohet SB. Deformability of stored red blood cells. Relationship to degree of packing. Transfusion 1982;22:96-101.

11. Beutler E, Kuhl W, West C. The osmotic fragility of erythrocytes after prolonged liquid storage and after reinfusion. Blood 1982;59:1141-1147.

12. Card RT, Mohandas N, Mollison PL. Relationship of posttransfusion viability to deformability of stored red cells. $\mathrm{Br} \mathrm{J}$ Haematol 1983;53:237-240.

13. Tinmouth A, Fergusson D, Yee IC, Hebert PC. Clinical consequences of red cell storage in the critically ill. Transfusion 2006;46:2014-2027.

14. Knight JA, Voorhees RP, Martin L, Anstall H. Lipid peroxidation in stored red cells. Transfusion 1992;32:354-357.

15. Hovav T, Yedgar S, Manny N, Barshtein G. Alteration of red cell aggregability and shape during blood storage. Transfusion 1999;39:277-281.

16. Berezina TL, Zaets SB, Morgan C, et al. Influence of storage on red blood cell rheological properties. J Surg Res 2002;102:6-12.

17. Jy W, Ricci M, Shariatmadar S, Gomez-Marin O, Horstman LH, Ahn YS. Microparticles in stored red blood cells as potential mediators of transfusion complications. Transfusion 2011;51:886893.

18. Bidot L, Jy W, Bidot C, Jr., et al. Microparticle-mediated thrombin generation assay: increased activity in patients with recurrent thrombosis. J Thromb Haemost 2008;6:913-919.

19. Jy W, Horstman LL, Wang F, Duncan RC, Ahn YS. Platelet factor 3 in plasma fractions: its relation to microparticle size and thromboses. Thromb Res 1995;80:471-482.

20. Goodnough LT. Risks of blood transfusion. Crit Care Med 2003;31(12 suppl):S678-S686.

21. Soderberg-Naucler C, Fish KN, Nelson JA. Reactivation of latent human cytomegalovirus by allogeneic stimulation of blood cells from healthy donors. Cell 1997;91:119-126. 
22. Bowden RA, Sayers M, Flournoy N, et al. Cytomegalovirus immune globulin and seronegative blood products to prevent primary cytomegalovirus infection after marrow transplantation. N Engl J Med 1986;314:1006-1010.

23. Raghavan M, Marik PE. Anemia, allogenic blood transfusion, and immunomodulation in the critically ill. Chest 2005;127:295307.

24. Goldman M, Webert KE, Arnold DM, Freedman J, Hannon J, Blajchman MA. Proceedings of a consensus conference: towards an understanding of TRALI. Transfus Med Rev 2005;19:2-31.

25. Benjamin RJ. Tracking TRALI in target populations. Blood 2011;117:4163-4164.

26. Kleinman S, Caulfield T, Chan P, et al. Toward an understanding of transfusion-related acute lung injury: statement of a consensus panel. Transfusion 2004;44:1774-1789.

27. Shander A, Popovsky MA. Understanding the consequences of transfusion-related acute lung injury. Chest 2005;128(5 suppl 2):598S-604S

28. Rizk A, Gorson KC, Kenney L, Weinstein R. Transfusion-related acute lung injury after the infusion of IVIG. Transfusion 2001;41:264-268

29. Reese EP Jr., McCullough JJ, Craddock PR. An adverse pulmonary reaction to cryoprecipitate in a hemophiliac. Transfusion 1975;15:583-588.

30. Suassuna JH, da Costa MA, Faria RA, Melichar AC. Noncardiogenic pulmonary edema triggered by intravenous immunoglobulin in cancer-associated thrombotic thrombocytopenic purpurahemolytic uremic syndrome. Nephron 1997;77:368-370.

31. Purdy FR, Tweeddale MG, Merrick PM. Association of mortality with age of blood transfused in septic ICU patients. Can J Anaesth 1997;44:1256-1261.

32. Offner PJ, Moore EE, Biffl WL, Johnson JL, Silliman CC. Increased rate of infection associated with transfusion of old blood after severe injury. Arch Surg 2002;137:711-717.

33. Edna TH, Bjerkeset T. Association between blood transfusion and infection in injured patients. J Trauma 1992;33:659-661.

34. Moore FA, Moore EE, Sauaia A. Blood transfusion. An independent risk factor for postinjury multiple organ failure. Arch Surg 1997; 132:620-625.

35. Agarwal N, Murphy JG, Cayten CG, Stahl WM. Blood transfusion increases the risk of infection after trauma. Arch Surg 1993; 128:171-177.

36. Claridge JA, Sawyer RG, Schulman AM, McLemore EC, Young JS. Blood transfusions correlate with infections in trauma patients in a dose-dependent manner. Am Surg 2002;68:566-572.

37. Malone DL, Dunne J, Tracy JK, Putnam AT, Scalea TM, Napolitano LM. Blood transfusion, independent of shock severity, is associated with worse outcome in trauma. J Trauma 2003;54:898-907.

38. Dunne JR, Malone DL, Tracy JK, Napolitano LM. Allogenic blood transfusion in the first 24 hours after trauma is associated with increased systemic inflammatory response syndrome (SIRS) and death. Surg Infect (Larchmt) 2004;5:395-404.

39. Wobbes T, Bemelmans BL, Kuypers JH, Beerthuizen GI, Theeuwes AG. Risk of postoperative septic complications after abdominal surgical treatment in relation to perioperative blood transfusion. Surg Gynecol Obstet 1990;171:59-62.

40. Chelemer SB, Prato BS, Cox PM Jr., O'Connor GT, Morton JR. Association of bacterial infection and red blood cell transfusion after coronary artery bypass surgery. Ann Thorac Surg 2002;73:138-142.

41. Leal-Noval SR, Jara-Lopez I, Garcia-Garmendia JL, et al. Influence of erythrocyte concentrate storage time on postsurgical morbidity in cardiac surgery patients. Anesthesiology 2003;98:815-822.
42. Leal-Noval SR, Rincon-Ferrari MD, Garcia-Curiel A, et al. Transfusion of blood components and postoperative infection in patients undergoing cardiac surgery. Chest 2001;119:14611468.

43. Shorr AF, Jackson WL, Kelly KM, Fu M, Kollef MH. Transfusion practice and blood stream infections in critically ill patients. Chest 2005;127:1722-1728.

44. Taylor RW, Manganaro L, O'Brien J, Trottier SJ, Parkar N, Veremakis C. Impact of allogenic packed red blood cell transfusion on nosocomial infection rates in the critically ill patient. Crit Care Med 2002;30:2249-2254.

45. Marik PE, Corwin HL. Efficacy of red blood cell transfusion in the critically ill: a systematic review of the literature. Crit Care Med 2008;36:2667-2674.

46. Chu RW. Leukocytes in blood transfusion: adverse effects and their prevention. Hong Kong Med J 1999;5:280-284.

47. Phelan HA, Gonzalez RP, Patel HD, et al. Prestorage leukoreduction ameliorates the effects of aging on banked blood. J Trauma 2010;69:330-337.

48. Silliman CC, Moore EE, Kelher MR, Khan SY, Gellar L, Elzi DJ. Identification of lipids that accumulate during the routine storage of prestorage leukoreduced red blood cells and cause acute lung injury. Transfusion 2011;xx:xx-xx.

49. Silliman CC, Clay KL, Thurman GW, Johnson CA, Ambruso DR. Partial characterization of lipids that develop during the routine storage of blood and prime the neutrophil NADPH oxidase. J Lab Clin Med 1994;124:684-694.

50. Silliman CC, Boshkov LK, Mehdizadehkashi Z, et al. Transfusion-related acute lung injury: epidemiology and a prospective analysis of etiologic factors. Blood 2003;101:454 462 .

51. Stec N, Shirey RS, Smith B, Kickler TS, Ness PM. The efficacy of performing red cell elution studies in the pretransfusion testing of patients with positive direct antiglobulin tests. Transfusion 1986;26:225-226.

52. Heddle NM, Klama LN, Griffith L, Roberts R, Shukla G, Kelton JG. A prospective study to identify the risk factors associated with acute reactions to platelet and red cell transfusions. Transfusion 1993;33:794-797.

53. Hebert PC, Fergusson D, Blajchman MA, et al. Clinical outcomes following institution of the Canadian universal leukoreduction program for red blood cell transfusions. JAMA 2003;289:19411949.

54. Dzik WH, Anderson JK, O'Neill EM, Assmann SF, Kalish LA, Stowell CP. A prospective, randomized clinical trial of universal WBC reduction. Transfusion. 2002;42:1114-1122.

55. Watkins TR, Rubenfeld GD, Martin TR, et al. Effects of leukoreduced blood on acute lung injury after trauma: a randomized controlled trial. Crit Care Med 2008;36:1493-1499.

56. Nathens AB, Nester TA, Rubenfeld GD, Nirula R, Gernsheimer TB. The effects of leukoreduced blood transfusion on infection risk following injury: a randomized controlled trial. Shock 2006;26:342-347.

57. Hurd TC, Dasmahapatra KS, Rush BF Jr., Machiedo GW. Red blood cell deformability in human and experimental sepsis. Arch Surg 1988;123:217-220.

58. Langenfeld JE, Livingston DH, Machiedo GW. Red cell deformability is an early indicator of infection. Surgery 1991;110:398404.

59. Baker CH, Wilmoth FR, Sutton ET. Reduced RBC versus plasma microvascular flow due to endotoxin. Circ Shock 1986;20:127139.

60. Rivers E, Nguyen B, Havstad S, et al. Early goal-directed therapy in the treatment of severe sepsis and septic shock. N Engl J Med 2001;345:1368-1377. 
61. Parsons EC, Hough CL, Seymour CW, Cooke CR, Rubenfeld GD, Watkins TR. Red blood cell transfusion and outcomes in patients with acute lung injury, sepsis and shock. Crit Care 2011;15:R221.

62. Silverman HJ, Tuma P. Gastric tonometry in patients with sepsis. Effects of dobutamine infusions and packed red blood cell transfusions. Chest 1992;102:184-188.

63. Marik PE, Sibbald WJ. Effect of stored-blood transfusion on oxygen delivery in patients with sepsis. JAMA 1993;269:30243029.

64. Vincent JL, Baron JF, Reinhart K, et al. Anemia and blood transfusion in critically ill patients. JAMA 2002;288:14991507.

65. Corwin HL, Gettinger A, Pearl RG, et al. The CRIT Study: Anemia and blood transfusion in the critically ill-current clinical practice in the United States. Crit Care Med 2004;32:39-52.

66. Hebert PC, Wells G, Tweeddale M, et al. Does transfusion practice affect mortality in critically ill patients? Transfusion Requirements in Critical Care (TRICC) Investigators and the Canadian Critical Care Trials Group. Am J Respir Crit Care Med 1997;155:1618-1623.

67. Glance LG, Dick AW, Mukamel DB, et al. Association between intraoperative blood transfusion and mortality and morbidity in patients undergoing noncardiac surgery. Anesthesiology 2011;114:283-292.

68. Asplund K. Haemodilution for acute ischaemic stroke. Cochrane Database Syst Rev 2002(4):CD000103.

69. Grotta J, Ackerman R, Correia J, Fallick G, Chang J. Whole blood viscosity parameters and cerebral blood flow. Stroke 1982;13:296-301.

70. Allport LE, Parsons MW, Butcher KS, et al. Elevated hematocrit is associated with reduced reperfusion and tissue survival in acute stroke. Neurology 2005;65:1382-1387.

71. Sacco S, Marini C, Olivieri L, Pistoia F, Carolei A. Contribution of hematocrit to early mortality after ischemic stroke. Eur Neurol 2007;58:233-238.

72. Irace C, Ciamei M, Crivaro A, et al. Hematocrit is associated with carotid atherosclerosis in men but not in women. Coron Artery Dis 2003;14:279-284.

73. Harrisond MJ, Pollock S, Kendall BE, Marshall J. Effect of haematocrit on carotid stenosis and cerebral infarction. Lancet 1981;2:114-115.

74. Lowe GD, Jaap AJ, Forbes CD. Relation of atrial fibrillation and high haematocrit to mortality in acute stroke. Lancet 1983;1:784786.

75. Wannamethee G, Perry IJ, Shaper AG. Haematocrit, hypertension and risk of stroke. J Intern Med 1994;235:163-168.

76. Diamond PT, Gale SD, Evans BA. Relationship of initial hematocrit level to discharge destination and resource utilization after ischemic stroke: a pilot study. Arch Phys Med Rehabil 2003;84:964-967.

77. Wade JP, Taylor DW, Barnett HJ, Hachinski VC. Hemoglobin concentration and prognosis in symptomatic obstructive cerebrovascular disease. Stroke 1987;18:68-71.

78. Tanne D, Molshatzki N, Merzeliak O, Tsabari R, Toashi M, Schwammenthal Y. Anemia status, hemoglobin concentration and outcome after acute stroke: a cohort study. BMC Neurol 2010;10:22.

79. Dexter F, Hindman BJ. Effect of haemoglobin concentration on brain oxygenation in focal stroke: a mathematical modelling study. Br J Anaesth 1997;79:346-351.

80. Kellert L, Martin E, Sykora M, et al. cerebral oxygen transport failure? Decreasing hemoglobin and hematocrit levels after ischemic stroke predict poor outcome and mortality: Stroke: Relevant impact of hemoglobin, hematocrit and transfusion (STRAIGHT) an observational study. Stroke 2011;42:1-6.
81. Karkouti K, Djaiani G, Borger MA, et al. Low hematocrit during cardiopulmonary bypass is associated with increased risk of perioperative stroke in cardiac surgery. Ann Thorac Surg 2005;80:1381-1387.

82. Bahrainwala ZS, Grega MA, Hogue CW, et al. Intraoperative hemoglobin levels and transfusion independently predict stroke after cardiac operations. Ann Thorac Surg 2011;91:1113-1138.

83. DeFoe GR, Ross CS, Olmstead EM, et al. Lowest hematocrit on bypass and adverse outcomes associated with coronary artery bypass grafting. Northern New England Cardiovascular Disease Study Group. Ann Thorac Surg 2001;71:769-776.

84. Savageau JA, Stanton BA, Jenkins CD, Klein MD. Neuropsychological dysfunction following elective cardiac operation. I. Early assessment. J Thorac Cardiovasc Surg 1982;84:585-594.

85. Kumar MA, Rost NS, Snider RW, et al. Anemia and hematoma volume in acute intracerebral hemorrhage. Crit Care Med 2009;37:1442-1447.

86. Sheth KN, Gilson AJ, Chang Y, et al. Packed red blood cell transfusion and decreased mortality in intracerebral hemorrhage. neurosurgery. 2011;68:1286-1292.

87. Wartenberg KE, Schmidt JM, Claassen J, et al. Impact of medical complications on outcome after subarachnoid hemorrhage. Crit Care Med 2006;34:617-624.

88. Solenski NJ, Haley EC Jr., Kassell NF, et al. Medical complications of aneurysmal subarachnoid hemorrhage: a report of the multicenter, cooperative aneurysm study. Participants of the Multicenter Cooperative Aneurysm Study. Crit Care Med 1995;23:1007-1017.

89. Springer MV, Schmidt JM, Wartenberg KE, Frontera JA, Badjatia N, Mayer SA. Predictors of global cognitive impairment 1 year after subarachnoid hemorrhage. Neurosurgery 2009;65:1043-1051.

90. Tseng MY, Hutchinson PJ, Kirkpatrick PJ. Effects of fluid therapy following aneurysmal subarachnoid haemorrhage: a prospective clinical study. Br J Neurosurg 2008;22:257-268.

91. De Georgia MA, Deogaonkar A, Mascha E, et al. Blood transfusion may worsen outcome following subarachnoid hemorrhage: results from IHAST. Stroke 2007;38:544.

92. Smith MJ, Le Roux PD, Elliott JP, Winn HR. Blood transfusion and increased risk for vasospasm and poor outcome after subarachnoid hemorrhage. J Neurosurg 2004;101:1-7.

93. Levine J, Kofke A, Cen L, et al. Red blood cell transfusion is associated with infection and extracerebral complications after subarachnoid hemorrhage. Neurosurgery 2010;66:312-318.

94. Kramer AH, Gurka MJ, Nathan B, Dumont AS, Kassell NF, Bleck TP. Complications associated with anemia and blood transfusion in patients with aneurysmal subarachnoid hemorrhage. Crit Care Med 2008;36:2070-2075.

95. Kahn JM, Caldwell EC, Deem S, Newell DW, Heckbert SR, Rubenfeld GD. Acute lung injury in patients with subarachnoid hemorrhage: incidence, risk factors, and outcome. Crit Care Med 2006;34:196-202.

96. Dumont AS, Dumont RJ, Chow MM, et al. Cerebral vasospasm after subarachnoid hemorrhage: putative role of inflammation. Neurosurgery 2003;53:123-135.

97. Dechant VE, Baio M, Boland T, et al. Increased risk of thrombosis following red blood cell transfusion in patients with subarachnoid hemorrhage. Neurocrit Care 2010;13:S14.

98. Oddo M, Milby A, Chen I, et al. Hemoglobin concentration and cerebral metabolism in patients with aneurysmal subarachnoid hemorrhage. Stroke 2009;40:1275-1281.

99. Lee EJ, Hung YC. Marked anemic hypoxia deteriorates cerebral hemodynamics and brain metabolism during massive intracerebral hemorrhage. J Neurol Sci 2001;190(1-2):3-10.

100. Hare GM, Mazer CD, Hutchison JS, et al. Severe hemodilutional anemia increases cerebral tissue injury following acute neurotrauma. J Appl Physiol 2007;103:1021-1029. 
101. Dhar R, Zazulia AR, Videen TO, Zipfel GJ, Derdeyn CP, Diringer MN. Red blood cell transfusion increases cerebral oxygen delivery in anemic patients with subarachnoid hemorrhage. Stroke 2009;40:3039-3044.

102. Diringer MN, Bleck TP, Hemphill JC $3^{\text {rd }}$, et al. Critical care management of patients following aneurysmal subarachnoid hemorrhage: Recommendations from the Neurocritical Care Society's Multidisciplinary Consensus Conference. Neurocrit Care 2011;15:211-240.

103. Naidech AM, Shaibani A, Garg RK, et al. Prospective, randomized trial of higher goal hemoglobin after subarachnoid hemorrhage. Neurocrit Care 2010;13:313-320.

104. Dunne JR, Malone D, Tracy JK, Gannon C, Napolitano LM. Perioperative anemia: an independent risk factor for infection, mortality, and resource utilization in surgery. J Surg Res 2002;102:237244.

105. Duane TM, Mayglothling J, Grandhi R, et al. The effect of anemia and blood transfusions on mortality in closed head injury patients. J Surg Res 2008;147:163-167.

106. McIntyre L, Hebert PC, Wells G, et al. Is a restrictive transfusion strategy safe for resuscitated and critically ill trauma patients? J Trauma 2004;57:563-568.

107. Zygun DA, Nortje J, Hutchinson PJ, Timofeev I, Menon DK, Gupta AK. The effect of red blood cell transfusion on cerebral oxygenation and metabolism after severe traumatic brain injury. Crit Care Med 2009;37:1074-1078.

108. Smith MJ, Stiefel MF, Magge S, et al. Packed red blood cell transfusion increases local cerebral oxygenation. Crit Care Med 2005;33:1104-1108.
109. Leal-Noval SR, Munoz-Gomez M, Arellano-Orden V, et al. Impact of age of transfused blood on cerebral oxygenation in male patients with severe traumatic brain injury. Crit Care Med 2008;36:1290-1296.

110. Leal-Noval SR, Rincon-Ferrari MD, Marin-Niebla A, et al. Transfusion of erythrocyte concentrates produces a variable increment on cerebral oxygenation in patients with severe traumatic brain injury: a preliminary study. Intensive Care Med 2006;32:1733-1740.

111. Bohman LE, Heuer GG, Macyszyn L, et al. Medical management of compromised brain oxygen in patients with severe traumatic brain injury. Neurocrit Care 2011;14:361-369.

112. Sarrafzadeh AS, Haux D, Ludemann L, et al. Cerebral ischemia in aneurysmal subarachnoid hemorrhage: a correlative microdialysis-PET study. Stroke 2004;35:638-643.

113. Vespa P, Bergsneider M, Hattori N, et al. Metabolic crisis without brain ischemia is common after traumatic brain injury: a combined microdialysis and positron emission tomography study. J Cereb Blood Flow Metab 2005;25:763-774.

114. Vespa PM. The implications of cerebral ischemia and metabolic dysfunction for treatment strategies in neurointensive care. Curr Opin Crit Care 2006;12:119-123.

115. Diringer MN, Videen TO, Yundt K, et al. Regional cerebrovascular and metabolic effects of hyperventilation after severe traumatic brain injury. J Neurosurg 2002;96:103-108.

116. Coles JP. Regional ischemia after head injury. Curr Opin Crit Care 2004;10:120-125.

117. Sena MJ, Rivers RM, Muizelaar JP, Battistella FD, Utter GH. Transfusion practices for acute traumatic brain injury: a survey of physicians at US trauma centers. Intensive Care Med 2009;35:480-488. 